\title{
Retinoblastoma treatment burden and economic cost: impact of age at diagnosis and selection of primary therapy
}

This article was published in the following Dove Press journal:

Clinical Ophthalmology

3 October 2012

Number of times this article has been viewed

\author{
Hassan A Aziz' \\ Charlotte E LaSenna ${ }^{2}$ \\ Michael Vigoda ${ }^{1,2}$ \\ Cristina Fernandes ${ }^{2}$ \\ William Feuer ${ }^{\prime}$ \\ Mohammed Ali Aziz-Sultan ${ }^{2}$ \\ Timothy G Murray ${ }^{1-3}$ \\ 'Bascom Palmer Eye Institute, \\ Miami, FL, USA; '2University of Miami, \\ Miami, FL, USA; ${ }^{3}$ Murray Ocular \\ Oncology \& Retina, Miami, FL, USA
}

Purpose: To follow the treatment history of patients with retinoblastoma to identify the trends in the number of hospital visits over time and the direct cost of medical care as determined by age at diagnosis and selected primary treatment modality.

Design: An Institutional Review Board (IRB) approved consecutive retrospective case series. Materials and methods: Records from the Bascom Palmer Eye Institute were reviewed to identify 115 eligible patients (176 eyes) with retinoblastoma who underwent treatment at the Ocular Oncology Service between 1995 and 2010 and were available for extended follow-up evaluation.

Results: Bilateral disease was present in 53\% $(\mathrm{N}=61)$ of all patients, and $79 \%(\mathrm{~N}=90)$ of patients were diagnosed in the first six months of life. Chemotherapy was used to treat $75 \%$ $(\mathrm{N}=86)$ of all patients and $95 \%(\mathrm{~N}=36)$ of patients diagnosed in the first six months of life. $100 \%(\mathrm{~N}=4)$ of patients presenting between the age of five and nine were enucleated. Per episode of care, the lowest-cost treatment strategy was enucleation, followed by focal laser therapy, systemic chemotherapy with planned enucleation, systemic chemotherapy, and lastly, intra-arterial melphalan chemotherapy.

Conclusion: Age at diagnosis is directly associated with the type of treatment chosen for retinoblastoma. The burden of retinoblastoma treatment on children and families is significant. The direct medical cost of intra-arterial chemotherapy per episode of care is comparable to systemic chemotherapy, but current strategies utilizing multiple planned episodes of intraarterial chemotherapy are significantly more costly and may be associated with less systemic side effects and similar favorable outcomes. At the Bascom Palmer Eye Institute, intra-arterial chemotherapy has quickly become the treatment of choice for globe conserving therapy of retinoblastoma.

Keywords: retinoblastoma, melphalan, intra-arterial chemotherapy, cost

\section{Introduction}

Retinoblastoma is the most common intraocular tumor in the pediatric age group, with an incidence of 11.8 per million children from birth to 4 years in the USA. ${ }^{1}$ With advancement in diagnosis and management, the survival rates of patients diagnosed with retinoblastoma have increased significantly, from $70 \%$ in 1970 to $95 \%$ in 2008 . $^{2,3}$

The patient's age at the time of diagnosis has a significant bearing on the progression and prognosis of retinoblastoma. Children with unilateral retinoblastoma are diagnosed at a mean age of 25 months, and children with bilateral disease are diagnosed at a mean age of 15 months. ${ }^{4}$ Patients who are diagnosed within 6 months of life commonly have advanced bilateral disease and a higher tendency to develop secondary tumors than those
Correspondence: Timothy G Murray Murray Ocular Oncology \& Retina, 6705 Red Road Suite 4I2, Miami, FL 33I43, USA

Tel + I 3054877470

Fax +l 7865674380

Email tmurray@murraymd.com 
diagnosed within the first year of life. ${ }^{5-7}$ Thus, retinoblastoma treatment may vary depending on the age of diagnosis.

Management of retinoblastoma has evolved over the past 2 decades. External beam radiation therapy is a globe conserving and vision preserving method of retinoblastoma treatment that is not widely used because it has been associated with an increased risk of secondary tumors. ${ }^{8-10}$ Enucleation, which is still the preferred treatment for advanced retinoblastoma, is associated with motility restrictions and risk of exposure, infection, and extrusion. ${ }^{11,12}$ Chemoreduction plus focal consolidative therapy with laser therapy is currently the main globe conserving treatment modality with favorable results and minimal side effects. ${ }^{13,14}$ Most recently, targeted intra-arterial melphalan chemotherapy has emerged as a new modality of globe-conserving treatment in retinoblastoma with excellent results. ${ }^{15,16}$

Outcomes for retinoblastoma patients depend on multiple factors, including age at diagnosis, disease stage at presentation, laterality, family history, and treatment strategy. This study follows the clinical history of patients with retinoblastoma to calculate the cost and frequency of hospital visits within an episode of care for each treatment modality.

\section{Methods}

\section{Patient demographics}

In accordance with the University of Miami's Institutional Review Board protocol, records from the Bascom Palmer Eye Institute were reviewed to identify patients with retinoblastoma who underwent treatment at the Ocular Oncology Service between 1995 and 2010. The following data were extracted: patients' date of birth, sex, date of diagnosis, family history, laterality of disease, Reese-Ellsworth group, dates of hospital visits, treatment information, and outcome. Patients who were referred to the Ocular Oncology Service after initial treatment outside the Bascom Palmer Eye Institute were excluded from the study to achieve a uniform treatment protocol in the study cohort. Patients lost to follow up were also excluded from the study for similar reasons.

After gathering all relevant data, patients were grouped according to age at presentation. Groups are defined as follows: less than 1 month, between 1 and 6 months, between 6 months and 1 year, 1 year, 2 years, 3 to 5 years, and 6 to 8 years. Hospital visits were then averaged for each age group at 6-month intervals over a 5-year period following diagnosis to determine the expected number of hospital visits for each age group.

\section{Treatment}

Patients with Reese-Ellsworth groups I to IV disease underwent four to nine cycles of systemic chemotherapy with vincristine $(0.05 \mathrm{mg} / \mathrm{kg}$ for patients younger than 1 year, $1.5 \mathrm{mg} / \mathrm{m}^{2}$ for those older than 1 year), etoposide $(5 \mathrm{mg} / \mathrm{kg}$ for patients $<1$ year, $150 \mathrm{mg} / \mathrm{m}^{2}$ for patients $>1$ year), and carboplatin $\left(20 \mathrm{mg} / \mathrm{kg}\right.$ for patients $<1$ year, $600 \mathrm{mg} / \mathrm{m}^{2}$ for patients $>1$ year), and patients with group $\mathrm{V}$ disease underwent six to ten cycles of the aforementioned drugs with or without cyclosporine. Patients who received cyclosporine received a decrease in the dosage of vincristine to minimize toxicity. The number of cycles of chemotherapy was a clinical determination made by the ophthalmologist based on the appearance of the fundus. In Reese-Ellsworth group $\mathrm{Vb}$ eyes, chemotherapy was discontinued once the vitreous seeds appeared calcified and inactive for two to three cycles. Cyclosporine was used only in patients with very extensive tumor seeding throughout the vitreous, whereas patients with local seeding received the three chemotherapeutic agents only.

The date of presentation was recorded as the first examination under anesthesia for the patient. The first cycle of chemotherapy was delivered within two weeks of this date. Patients underwent examinations under anesthesia every 3 to 4 weeks while undergoing chemotherapy. At each visit, the status of each individual tumor and any vitreous seeds were recorded. All tumors underwent laser diode ablation during these examinations until tumors were observed to be inactive. Funduscopic examinations were performed every 3 to 4 weeks with photographs over a period of 6 months to monitor signs of recurrence (eg, new tumor foci, new fishflesh appearance, new collection of subretinal fluid, and new subretinal or vitreous seeds).

Laser therapy was delivered with an IRIS diode laser $(810 \mathrm{~nm})$ (Iridex Corp, Mountain View, CA). A 1.2-mm spot size was aimed through a dilated pupil using an indirect ophthalmoscope and a 20-diopter lens. The laser was set at $350 \mathrm{~mW}$ initially, and then the power was increased as necessary until the tumor achieved a gray-white appearance. The entire surface of the tumor was treated, including surrounding areas, to ensure that no portion of the tumor was missed. Patients requiring chemotherapy received treatments several hours after emerging from anesthesia.

For patients receiving intra-arterial melphalan, dosage was calculated according to the Mosteller formula by multiplying the Body Surface Area by $16 \mathrm{mg} / \mathrm{m}^{2}$. Patients were placed under general anesthesia, a heparin bolus ( 60 units $/ \mathrm{kg} \mathrm{IV}$ ) was given to anticoagulate the patients, and the activated clotting time was measured hourly with additional heparin boluses to keep it between 200 and 250 seconds. Under fluoroscopic $\mathrm{X}$-ray guidance, a $4 \mathrm{~F}$ guide catheter was maneuvered over 
a wire through the aortic arch into the right external and internal carotid arteries, through which digital subtracted angiography was performed to assess vascular supply to the orbit. A Marathon microcatheter (EV3, Irvine, CA) was then advanced over a Mirage microguidewire (EV3) and into the ostium of the ophthalmic artery where a selective ophthalmic artery angiography was performed. The desired dose of melphalan was diluted in $30 \mathrm{MI}$ of normal saline and infused by pulse injection over 30 minutes. Ophthalmic artery and right internal carotid artery angiography were repeated to rule out any inadvertent thromboembolic episodes.

\section{Mortality}

The survival rate in our case series was $100 \%$.

\section{Visual results}

All visual acuity measurements of the treated eyes were taken with a standardized Snellen chart at a distance in a formal examination by the same ophthalmologist as soon as the patient was old enough to participate. The visual acuity from the better-seeing eye was used to determine the visual utility.

\section{Medical costs}

The cost estimate for each treatment strategy was calculated by the episode of care. In this study, the episode of care was defined as an estimate of the direct medical cost that was required for different treatment modalities, plus the cost of EUAs until the patient reached clinical remission. Estimates are meant to represent the direct hospital charge for the average patient within each treatment category. Cost data for each procedure was collected from the Department of Revenue Cycle Services at Jackson Memorial Hospital and Department of Billing and Collections at Bascom Palmer Eye Institute. The cost of treatment by planned enucleation includes the cost of surgery and hospital visits; focal laser therapy includes the cost of EUAs with focal laser treatment and hospital visits; chemotherapy includes the cost of hospital visits as well as therapy; chemotherapy and planned enucleation includes chemotherapy, surgery, and hospital visits; intra-arterial melphalan treatment includes one EUA and unilateral and bilateral melphalan treatments (including one, three, and six cycles of melphalan).

\section{Results}

Of the 115 patients ( 61 female, 54 male), age of presentation ranged from birth to 9 years (Mean $=17$ months). The percentage of patients with bilateral disease at diagnosis and last follow up was 48\% ( $\mathrm{N}=55)$ and $53 \%(\mathrm{~N}=61)$, respectively. Follow up ranged from 9 months to 12 years $($ Mean $=57.4)$. The 115 patients underwent 1146 total EUAs $($ Mean $=10)$ in the first year and 503 total EUAs $($ Mean $=4.4)$ in the second (Table 1).

Patient data were grouped and analyzed according to age at presentation, birth to 6 months, 6 to 12 months, 1 to 2 years, 2 to 3 years, 3 to 5 years, and 5 to 9 years. Bilateral disease was present in $53 \%(\mathrm{~N}=61)$ of all patients and $79 \%$ $(\mathrm{N}=30)$ of patients diagnosed in the first 6 months of life (Table 2). Chemotherapy was used to treat $75 \%(\mathrm{~N}=86)$ of all patients and $95 \%(\mathrm{~N}=36)$ of patients diagnosed in the first 6 months of life (Table 3 ). Out of 176 eyes, a total of 70 eyes (40\%) underwent enucleation, of which 29 (61\%) were primary enucleation. All four patients diagnosed between the age of five and nine were enucleated. There was a mean of 167 days from diagnosis to enucleation (range $=0-1529$ ) (Table 4).

Patients with unilateral disease were grouped by treatment modality: enucleation only $(\mathrm{N}=20)$, focal laser therapy only $(\mathrm{N}=\operatorname{six})$, chemotherapy $(\mathrm{N}=13)$, and chemotherapy with

Table I Patient demographics

\begin{tabular}{ll}
\hline No of patients & $\mathbf{N}=1 \mathrm{II}$ \\
$0-<6$ months & $33 \%(\mathrm{~N}=38)$ \\
$6-<12$ months & $23 \%(\mathrm{~N}=26)$ \\
$\mathrm{I}-<2$ years & $22 \%(\mathrm{~N}=25)$ \\
$2-<3$ years & $5 \%(\mathrm{~N}=6)$ \\
$3-<5$ years & $14 \%(\mathrm{~N}=16)$ \\
$5-9$ years & $3 \%(\mathrm{~N}=4)$ \\
No of eyes & $\mathbf{N}=176$ \\
$0-<6$ months & $39 \%(\mathrm{~N}=68)$ \\
$6-<12$ months & $23 \%(\mathrm{~N}=41)$ \\
$\mathrm{I}-<2$ years & $20 \%(\mathrm{~N}=35)$ \\
$2-<3$ years & $5 \%(\mathrm{~N}=8)$ \\
$3-<5$ years & $11 \%(\mathrm{~N}=20)$ \\
$5-9$ years & $2 \%(\mathrm{~N}=4)$ \\
Laterality of disease at presentation & \\
Unilateral & $52 \%(\mathrm{~N}=60)$ \\
Bilateral & $48 \%(\mathrm{~N}=55)$ \\
Laterality of disease final & \\
Unilateral & $47 \%(\mathrm{~N}=54)$ \\
Bilateral & $53 \%(\mathrm{~N}=6 \mathrm{I})$ \\
Age at presentation (months) & \\
Mean & 17.1 \\
Standard deviation & 18.3 \\
Median & 10.5 \\
Range & $0-98.76$ \\
Follow up (months) & \\
Mean & 57.4 \\
Standard deviation & 32.7 \\
Median & 49.6 \\
Range & $9-139$ \\
\hline
\end{tabular}


Table 2 Percent of patients with bilateral disease development by age at diagnosis

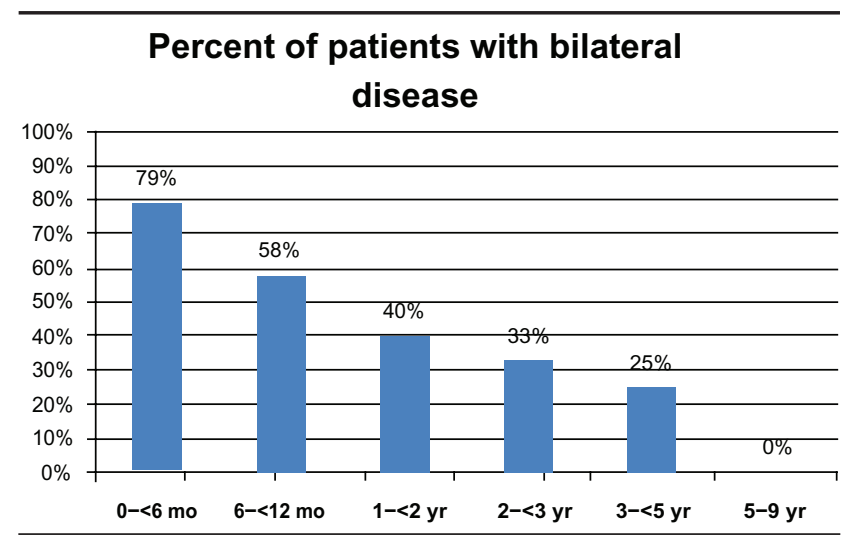

planned enucleation $(\mathrm{N}=20)$. For each treatment type, the average number of hospital visits was followed at intervals of 6 months over the course of 5 years. Comparison of trends in the frequency of hospital visits revealed that all treatment modalities eventually plateau at two hospital visits per year. Treatment via enucleation only was the first to plateau, at 12 months, focal laser plateaued at 18 months, chemotherapy plateaued at 24 months, and chemotherapy with planned enucleation plateaued at 36 months (Figure 1).

The average hospital charge cost per episode of care for each treatment type was calculated. These values were compared to the average cost of 1, 3 and 6 doses of unilateral and bilateral intra-arterial melphalan therapy. Moreover, the mean follow up visits for the first and second year of each treatment type was calculated (Table 5).

\section{Discussion}

This report describes the relationships between age at diagnosis, number of follow-up visits, treatment type, and

Table 3 Percent of patients who underwent chemotherapy by age at diagnosis

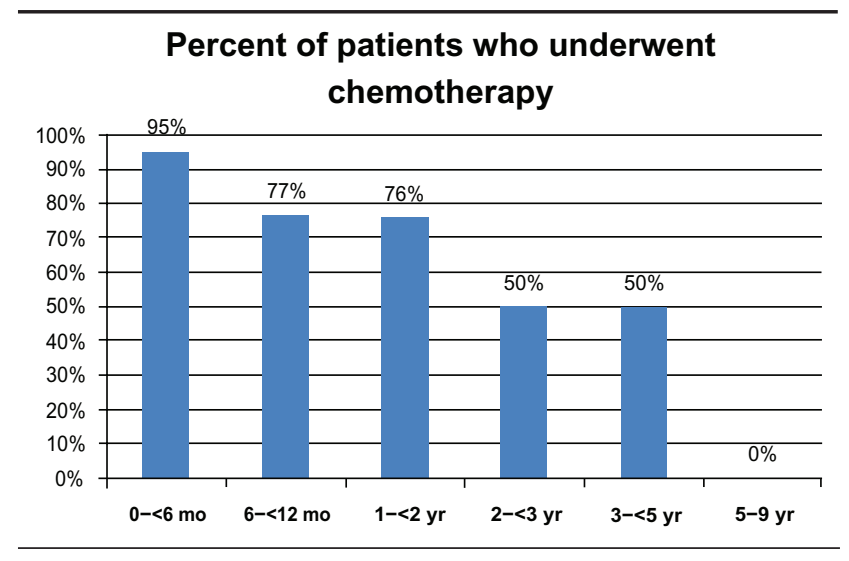

Table 4 Percent of eyes with primary enucleation by age of diagnosis and time from diagnosis until enucleation

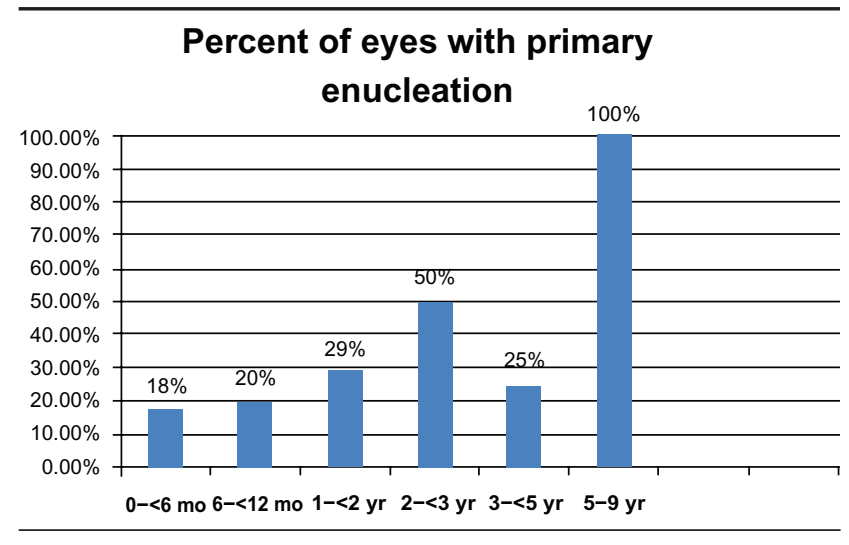

direct medical costs of retinoblastoma treatment. In reviewing patient records, we identified the following trends in the progression of retinoblastoma according to age at diagnosis. The occurrence of bilateral disease decreases with increasing age of presentation. Bilateral disease was most prevalent in patients diagnosed in the first 6 months of life. Treatment with chemotherapy was the preferred method for patients aged under 1 year. None of the patients diagnosed after 5 years of age were treated with chemotherapy, compared to $50 \%$ of patients 2 to 5 years old and $95 \%$ of patients less than 6 months old at presentation. Treatment via enucleation was the preferred treatment strategy for patients over 5 years. The use of enucleation as a treatment strategy was chosen more often as age at diagnosis increased; however, only $24 \%$ of patients received this treatment overall.

Per episode of care, the lowest-cost treatment strategy per episode of care was enucleation, followed by focal laser therapy, chemotherapy with planned enucleation, chemotherapy, and intra-arterial melphalan. Enucleation is the

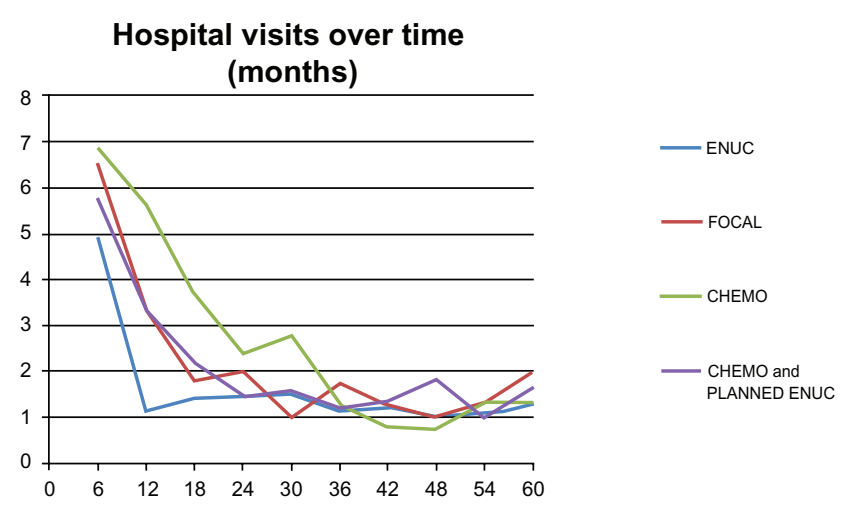

Figure I The number of hospital visits over the period of 60 months for different treatment types.

Abbreviations: CHEMO, chemotherapy; ENUC, enucleation. 
Table 5 Direct medical costs including physician fees for different treatment types

\begin{tabular}{|c|c|c|c|}
\hline & Episode of care & First year & Second year \\
\hline \multirow[t]{2}{*}{ Chemotherapy ( 9 cycles) } & $\$ 17,000+10$ EUAs & I2.46 avg EUAs (unilateral) & 6.06 avg EUAs \\
\hline & Total $\$ 253,000$ & & \\
\hline \multirow[t]{3}{*}{ Chemotherapy with enucleation } & $\$ 17,000+\$ 28,000+$ & 9.04 avg EUAs (unilateral) & 3.68 avg EUAs (unilateral) \\
\hline & 10 EUAs & & \\
\hline & Total $\$ 281,000$ & & \\
\hline \multirow[t]{2}{*}{ Enucleation only } & $\$ 28,000+2$ EUAs & 6.05 avg EUAs (unilateral) & 2.85 avg EUAs \\
\hline & Total $\$ 48,000$ & & \\
\hline \multirow[t]{2}{*}{ Focal laser therapy } & $\$ 10,250$ (EUA + laser) & 9.2 avg EUAs (unilateral) & 3.8 avg EUAs \\
\hline & Total $\$ 100,250$ & & \\
\hline \multirow[t]{2}{*}{ Melphalan treatment unilateral $\times I$} & $\$ 40,000+2$ EUAs & & \\
\hline & Total $\$ 60,000$ & & \\
\hline \multirow[t]{2}{*}{ Melphalan treatment unilateral $\times 3$} & $\$ 120,000+4$ EUAs & & \\
\hline & Total $\$ 160,000$ & & \\
\hline \multirow[t]{2}{*}{ Melphalan treatment unilateral $\times 6$} & $\$ 240,000+7$ EUAs & & \\
\hline & Total $\$ 310,000$ & & \\
\hline \multirow[t]{2}{*}{ Melphalan treatment bilateral $\times \mathrm{I}$} & $\$ 60,000+2$ EUAs & & \\
\hline & Total $\$ 80,000$ & & \\
\hline \multirow[t]{2}{*}{ Melphalan treatment bilateral $\times 3$} & $\$ 180,000+4$ EUAs & & \\
\hline & Total $\$ 220,000$ & & \\
\hline \multirow[t]{2}{*}{ Melphalan treatment bilateral $\times 6$} & $\$ 360,000+7$ EUAs & & \\
\hline & Total $\$ 430,000$ & & \\
\hline
\end{tabular}

Abbreviations: Avg, average; EUA, examination under anesthesia.

least expensive modality of treatment with the least number of follow-up visits; it is less favored in the developed world where globe conserving treatment options are available. Not all retinoblastoma eyes are amenable to focal treatment alone, and this strategy failed in two patients who were then enucleated. Advanced disease with delayed presentations would still need to have chemoreduction followed by enucleation.

The cost per episode of both systemic chemotherapy and three cycles of intra-arterial melphalan were comparable. In our experience, systemic chemotherapy is associated with a higher frequency of systemic side effects and potential for future hospitalizations, which add to the overall cost of the treatment. ${ }^{17,18}$ Intra-arterial melphalan has been associated with multiple short-term complications, including potentially blinding vascular occlusions. ${ }^{19}$ Complications may be minimized under the care of an experienced team.

The limitations in this study result from the retrospective case-based design. Further, nonmedical and indirect costs, such as the cost of travel and lost time, were not included in this study.

Age of presentation was directly correlated with the treatment modalities chosen for patients with retinoblastoma. With the limited systemic side effects profile, favorable outcomes, and accessibility to advanced interventional radiologic care, intra-arterial melphalan therapy has quickly replaced systemic chemotherapy as the globe conserving treatment of choice for advanced retinoblastoma.

\section{Disclosure}

The authors have no financial interest in any product or piece of equipment discussed in this article.

\section{References}

1. Broaddus E, Topham A, Singh AD. Incidence of retinoblastoma in the USA: 1975-2004. Br J Ophthalmol. 2009;93(1):21-23.

2. Ellsworth RM. The practical management of retinoblastoma. Trans Am Ophthalmol Soc. 1969;67:462-534.

3. Broaddus E, Topham A, Singh AD. Survival with retinoblastoma in the USA: 1975-2004. Br J Ophthalmol. 2009;93(1):24-27.

4. Abramson DH, Ellsworth RM, Grumbach N, Kitchin FD. Retinoblastoma: survival, age at detection and comparison 1914-1958, 1958-1983. J Pediatr Ophthalmol Strabismus. 1985;22(6):246-250.

5. Abramson DH, Servodidio CA. Retinoblastoma in the first year of life. Ophthalmic Paediatr Genet. 1992;13(4):191-203.

6. Abramson DH, Notterman RB, Ellsworth RM, Kitchin FD. Retinoblastoma treated in infants in the first six months of life. Arch Ophthalmol. 1983; 101(9):1362-1366.

7. David H Abramson, Ted T Du, Katherine L. Beaverson. (Neonatal) Retinoblastoma in the first month of life. Arch Ophthalmol. 2002;120: 738-742.

8. Moll AC, Imhof SM, Schouten-Van Meeteren AY, et al. Second primary tumors in hereditary retinoblastoma: a register-based study, 1945-1997. Is there an age effect on radiation-related risk? Ophthalmology. 2001;108(6):1109-1114.

9. Wong FL, Boice JD Jr, Abramson DH, et al. Cancer incidence after retinoblastoma. Radiation dose and sarcoma risk. JAMA. 1997;27(15): 1262-1267.

10. Kleinerman RA, Tucker MA, Tarone RE, et al. Risk of new cancers after radiotherapy in long-term survivors of retinoblastoma: an extended follow-up. J Clin Oncol. 2005;23(10):2272-2279.

11. Hornblass A, Biesman BS, Eviatar JA. Current techniques of enucleation: a survey of 5439 intraorbital implants and a review of the literature. Ophthal Plast Reconstr Surg 1995;11:77-86. 
12. Shields CL, Uysal Y, Marr BP, et al. Experience with the polymercoated hydroxyapatite implant following enucleation in 126 patients. Ophthalmology. 2007;114:367-373.

13. Shields CL, Mashayekhi A, Cater J, et al. Chemoreduction for retinoblastoma analysis of tumor control and risks for recurrence in 457 tumors. Am J Ophthalmol. 2004;138:329-337.

14. Schiavetti A, Hadjistilianou T, Clerico A, et al. Conservative therapy in intraocular retinoblastoma: response/recurrence rate. J Pediatr Hematol Oncol. 2005;27(1):3-6.

15. Gobin YP, Dunkel IJ, Marr BP, Brodie SE, Abramson DH. Intraarterial chemotherapy for the management of retinoblastoma: four-year experience. Arch Ophthalmol. 2011;129(6):732-737.

16. Venturi C, Bracco S, Cerase A, et al. Superselective ophthalmic artery infusion of melphalan for intraocular retinoblastoma: preliminary results from 140 treatments. Acta Ophthalmol. 2012 Jan 23. doi: 10.1111/j.1755-3768.2011.02296.x. [Epub ahead of print]
17. Vajzovic LM, Murray TG, Aziz-Sultan MA, et al. Supraselective intraarterial chemotherapy: evaluation of treatment-related complications in advanced retinoblastoma. Clin Ophthalmol. 2011;5:171-176.

18. Benz MS, Scott IU, Murray TG, Kramer D, Toledano S. Complications of systemic chemotherapy as treatment of retinoblastoma. Arch Ophthalmol. 2000;118(4):577-578.

19. Shields CL, Bianciotto CG, Jabbour $P$, et al. Intra-arterial chemotherapy for retinoblastoma: report No. 2 treatment complications. Arch Ophthalmol. 2011;129(11):1407-1415.
Clinical Ophthalmology

\section{Publish your work in this journal}

Clinical Ophthalmology is an international, peer-reviewed journal covering all subspecialties within ophthalmology. Key topics include: Optometry; Visual science; Pharmacology and drug therapy in eye diseases; Basic Sciences; Primary and Secondary eye care; Patient Safety and Quality of Care Improvements. This journal is indexed on

\section{Dovepress}

PubMed Central and CAS, and is the official journal of The Society of Clinical Ophthalmology (SCO). The manuscript management system is completely online and includes a very quick and fair peer-review system, which is all easy to use. Visit http://www.dovepress.com/ testimonials.php to read real quotes from published authors. 